\title{
A participação feminina em mercados ilícitos de drogas no Vale do São Francisco, no Nordeste brasileiro
}

Paulo Cesar Pontes Fraga e Joyce Keli do Nascimento Silva

À guisa de introdução: 0 plantio de cannabis e o tráfico de drogas como ilegalismos diferenciados

O tráfico de drogas e o cultivo de determinadas plantas utilizadas para a produção de substâncias psicoativas proscritas são atividades específicas que demandam organizaçôes diferenciadas, envolvimentos peculiares de atores e desenvolvimento de tarefas singulares (Afsahi, 2015; Bloomer, 2009). No âmbito da economia ilegal das drogas, esses dois elos da cadeia produtiva e de circulação da mercadoria causam efeitos diferenciados e formas de repressão e arranjos institucionais ou ilegais específicos nas pessoas envolvidas ou não nos meandros dessas atividades. A legislação brasileira, no entanto, trata essas ações como análogas, prevendo a mesma pena para condenados por participar em uma dessas atividades. Apesar de o tratamento legal ser similar, trata-se de ilegalismos distintos (Foucault, 1997; 2015), cuja gestão diferencial é realizada peculiarmente pelas agências de controle do crime. Nas últimas décadas, estratégias distintas foram utilizadas para enfrentar o tráfico de drogas e o plantio extensivo de cannabis no Brasil (Fraga e Silva, 2016). Esses enfrentamentos produziram reações diversificadas pelos indivíduos envolvidos no tráfico e no plantio, acarretando a formação de novas redes, de alianças, a emergência de atores e a reorganização das atividades e das ações.

Um de seus efeitos foi a participação mais efetiva de mulheres nessas atividades. $\mathrm{O}$ crescente envolvimento feminino nos últimos anos representou uma das consequências 
mais marcantes das formas de gestão desses ilegalismos no Brasil. Estatísticas prisionais e pesquisas acadêmicas evidenciam a trajetória ascendente do encarceramento de mulheres, ressaltando-se a inserção delas nos mercados ilícitos de drogas (Brasil, 2015). Contudo, essa inserção ainda permanece dissociada de papéis de maior destaque na articulação e na organização de redes criminosas, e, em geral, acontece através da ocupação de posições subalternas ou coadjuvantes no crime (Soares e Ilgenfritz, 2002; Frinhani, 2004; Moki, 2005; Guedes, 2006; Braunstein, 2007). Algumas pesquisas, entretanto, apontam o incipiente protagonismo feminino, caracterizado pela menor dependência de uma figura masculina nos últimos anos (Campos, 2015; Helpes, 2015; Grillo, 2008). Outros estudos apontam a aplicação de penas mais duras às mulheres envolvidas com o tráfico de drogas pela justiça (Boiteux, 2015; Silva, 2015). A polícia também passou a perseguir mais contundentemente pessoas do sexo feminino, principalmente em ações rotineiras em áreas urbanas de grandes e médias cidades (Silva, 2015; Fraga, 2015). Em relação ao plantio, a maior participação feminina está atrelada ao aumento da produção no modo de agricultura familiar em virtude de sua reorganização por conta da repressão policial (Fraga, Cunha e Carvalho, 2014).

Essas mudanças podem ser explicadas pela sedimentação da política de "combate às drogas”. As diferenciações desse ilegalismo, notadamente a partir dos anos de 1980, favoreceram o crescimento de uma divisão do trabalho nesse mercado ilegal (Fraga, 2015; Misse, 1999), com o aumento do número de mulheres, crianças e adolescentes envolvidos com o narcotráfico. Esses atores passaram a exercer as funções sobre as quais recaem os maiores riscos e uma parcela ínfima dos recursos financeiros da atividade, em funções como "vapores", "esticas", "mulas", “aviões", "fogueteiros" e "olheiros" (D’élia Filho, 2007; Barbosa, 1998), no caso do comércio, ou o de "feira”, "boiadeiro", "sementeira", no caso do plantio (Fraga e Iulianelli, 201 1; Fraga, Cunha e Carvalho, 2014).

Nesse sentido, mais do que restringir os ilegalismos, as agências os diferenciam internamente riscando os "limites de tolerância", que dão terreno para alguns, enquanto pressionam, excluem ou neutralizam outros. Telles e Hirata (2010, pp. 41 42) chamam a atenção para a face política da gestão diferencial dos ilegalismos, que circunscreve "dispositivos", "campos de força" e "jogos de poder" territorializados, atuantes na demarcação entre o legal e o ilegal, bem como na regulação dos mercados informais e ilegais. Nos mercados de drogas destacam-se os agenciamentos que variam entre a "transgressão consentida", os "mercados de proteção-extorsão", a "repressão" e a "exposição à morte pelo uso da violência extralegal" pela força policial (Telles e Hirata, 2010, pp. 41-42).

Nas últimas décadas, observaram-se mudanças significativas na criminalidade atrelada ao tráfico de drogas no Brasil, tendo como consequências mais visíveis, 
além do incremento da participação feminina, a interiorização e o papel que drogas como o crack passaram a ter na dinamização desse mercado. Esses dois fatores concorrem para moldar esse ilegalismo, implicando maior violência policial e conflito entre quadrilhas.

A política antidrogas brasileira influenciou a conformação dos mercados ilícitos de drogas, definindo os campos de força e os jogos de poder e afetando as demais práticas inseridas nas teias da ilegalidade e a forma das sociabilidades nas comunidades afetadas. As políticas e as ações que buscam a abstinência e a abstenção das drogas não conseguiram "proteger" a saúde pública e acabaram agravando a situação social dos países periféricos, marcados pela desigualdade e exclusão social, como é o caso do Brasil e dos demais países em desenvolvimento (Boiteux, 2009).

Para algumas autoras, as mulheres são o elo mais fraco dessa política repressiva: em geral, elas não praticaram crime violento, mas são condenadas a penas elevadas, pois " $35 \%$ delas receberam penas entre quatro e oito anos, $45 \%$ em regime fechado" (Boiteux, 2015), ou sofrem maior repressão por parte das agências de controle (Helpes, 2015).

Em sua maioria, provenientes dos mais baixos estratos sociais, as mulheres presas são vitimadas por uma segunda exclusão social, marcada pela diferenciação de papéis de gênero (Moki, 2005, p. 85). Assim, o pertencimento ao gênero feminino e a caracterização como traficante no processo penal conduzem a uma dupla rotulação (Becker, 2008) e estigmatização das mulheres (Goffman, 1988), moldando caminhos (Kokoreff, 2005): são vistas como antítese do feminino e como criminosas, além de lhes atribuírem marcas de menos valia associadas à socialmente difundida interpretação da maior gravidade e periculosidade do crime de tráfico. E quando não estão relegadas à invisibilidade e à segregação social, as mulheres encarceradas são repudiadas por grande parcela da sociedade (Soihet, 1989).

Por outro lado, os companheiros envolvidos no plantio são inclinados a preservar as mulheres, tendo em vista o papel feminino não só na estrutura da família, mas também na reprodução da agricultura familiar(Fraga, 2016). São facetas diferenciadas da mesma lógica de repressão e de administração dos ilegalismos. A prisão e a condenação de mulheres por plantio de cannabis são menos recorrentes. No entanto, a mulher, embora tenha uma participação menos visível, possui funções importantes na divisão de trabalho. Esse elemento é complexo, pois deve ser analisado pelo contexto das práticas de gestão do ilegalismo. Significa compreender que a não repressão contra a mulher é parte de uma estratégia política que pode mudar de acordo com os enfrentamentos a serem definidos pelas agências de controle.

Feitas essas considerações iniciais e reconhecendo a necessidade de estudos aprofundados sobre a participação feminina nos mercados ilegais de drogas, em especial 
em cidades do interior do Nordeste brasileiro, neste artigo são apresentadas reflexões sobre dados de pesquisas apoiadas pelo CNPq e pela Fapemig que têm por objeto a participação feminina no comércio de drogas e no plantio de cannabis na região do Submédio e Médio São Francisco.

As pesquisas originais, em que se baseiam os dados explorados neste artigo, empregaram metodologias qualitativas variadas, nos municípios de Petrolina, Orocó, Cabrobó e Belém do São Francisco, em Pernambuco, e nos municípios de Juazeiro e Curaçá, na Bahia. Esses municípios ocupam posição de destaque na produção e no escoamento da cannabis da região conhecida como "Polígono da Maconha"1 e em áreas próximas, apresentam crescimento relevante do consumo e do tráfico de drogas e contam com dois estabelecimentos prisionais femininos, um em Petrolina e outro em Juazeiro.

Salientamos que a população carcerária feminina desses estados acompanhou a tendência de crescimento verificada no contexto nacional, haja vista que, no período entre 2007 e 2014, o incremento no número de presas foi de 101\% em Pernambuco e de $94 \%$ na Bahia, com destaque para a prática dos crimes de drogas (Brasil, 2015). Além disso, a Região do Submédio e Médio São Francisco possui a especificidade de verificar o aumento do consumo e do tráfico de drogas, notadamente a maconha e o crack, nos últimos anos, e, também, de ser a principal região produtora de cannabis, matéria-prima para a produção da maconha e do haxixe (Rodrigues e Ribeiro, 2014; Fraga, 2015).

A análise apresentada neste artigo concentra-se nos relatos de vida de três mulheres presas por tráfico de drogas no Conjunto Penal de Juazeiro, Bahia, e de três mulheres que, em algum momento de suas vidas, estiveram envolvidas em atividades relacionadas com o cultivo ilícito de cannabis em municípios do Submédio e Médio São Francisco.

Foram enviadas cartas ao juiz da Vara de Execuções Penais da Comarca de Juazeiro e ao diretor do estabelecimento prisional solicitando autorização para a realização das entrevistas com mulheres presas por tráfico na região. Uma vez concedida a autorização, foram entrevistadas as internas que manifestaram anuência em colaborar com a pesquisa, respeitando os preceitos éticos de participação voluntária, de informação dos objetivos da pesquisa e de manter em sigilo a identidade das entrevistadas.

1. Essa região destaca-se como polo produtor de cannabis e está localizada no entroncamento de quatro estados da federação: Bahia, Pernambuco, Alagoas e Sergipe (a Polícia Federal incluiu o Ceará recentemente), abarcando aproximadamente $40.000 \mathrm{~m}^{2}$, metade destes em Pernambuco. 
Quanto à identificação das mulheres envolvidas nos plantios ilícitos, enfrenta-se o problema da identificação dos membros dessas "populações ocultas", devido à natureza sensível dos seus comportamentos (Salganik e Heckathorn, 2004). Nesse sentido, o caminho metodológico escolhido foi a técnica da "amostragem em bola de neve" (snowball sampling), que emprega cadeias de referência, uma espécie de rede em que os participantes iniciais de um estudo, os informantes-chave, indicam novos participantes, colaborando para a construção da rede de entrevistados, até que seja alcançado o objetivo proposto (Heckathorn, 1997; Vinuto, 2014). Assim, foram feitas entrevistas com diversos atores integrantes das redes ilícitas que compõem as atividades de cultivo e distribuição da cannabis na Região do Submédio e Médio São Francisco, a fim de identificar mulheres com histórico de participação no plantio ilícito. Cada uma delas concedeu três entrevistas, por meio das quais foram traçadas suas trajetórias biográficas (Fraga, 2015; Fraga e Silva, 2015).

Foram realizadas entrevistas em profundidade (Poupart, 2008), destinadas a verificar elementos objetivos e subjetivos das relações estabelecidas entre essas mulheres com instituições e atores ligados ou não à atividade ilícita (Dubar, 1998). Recorremos às noções de "trajetórias biográficas" (Idem) e de chaminement (Kokoreff, 2005) como elementos analíticos, para compreender a influência de aspectos das relações familiares, laborais, institucionais e interacionais sobre a inserção de mulheres nos mercados de drogas, seja no comércio ou no plantio de cannabis. Percebemos, assim, que, apesar de o tráfico e o plantio na região estudada serem atividades com participação predominantemente masculina, a inserção feminina merece destaque por envolver o desempenho de funções específicas que, dependendo do contexto, podem ou não levar as mulheres a construir uma carreira criminal, bem como conferir-lhes maior ou menor visibilidade para os agentes da repressão policial.

A seguir, apresentamos uma síntese das histórias de vida dessas mulheres, bem como as conclusões preliminares resultantes de sua análise. Ao longo do texto, os nomes de pessoas utilizados para identificar as entrevistadas são fictícios, com vistas à preservação das identidades e da segurança pessoal de cada uma. Todas colaboraram espontaneamente com seus depoimentos, tendo sido respeitados os preceitos éticos para a realização de pesquisas acadêmicas.

O objetivo é contribuir para a discussão sobre as relações existentes entre a condição de gênero e os mecanismos, as práticas e os atores dos mercados ilícitos de drogas na região, como também analisar dois aspectos relacionados com a gestão dos ilegalismos atrelados às drogas em contextos distintos: a qualidade da participação feminina nas atividades de plantio e de tráfico e os efeitos diferenciados produzidos nessas atividades para as mulheres em cidades do sertão baiano e pernambucano. 
A participação feminina no tráfico de drogas em municípios do Submédio e Médio São Francisco

Nos últimos anos, foram realizados alguns estudos sobre a problemática da criminalidade associada às drogas, sobre seus mecanismos e especificidades na região do Submédio e Médio São Francisco (Oliveira, 2007; Moreira, 2007; Nóbrega Júnior, 2010; Fraga e Iulianelli, 2011; Freire et al., 2014; Rodrigues e Ribeiro, 2014). Todavia, a maioria desses estudos não adota uma perspectiva que privilegie a análise da participação feminina na produção, no comércio e na distribuição de drogas ilícitas. Os estudos que abordam a questão da criminalidade feminina na região se preocupam efetivamente com as políticas públicas e a situação carcerária de mulheres internas em estabelecimentos prisionais (Barros et al., 2007; Santos, 2009; Oliveira, 2015).

Diante das estatísticas que destacam o crescente aprisionamento de mulheres por envolvimento no tráfico (Brasil, 2015), uma questão relevante está em desvendar os fatores determinantes do ingresso e da permanência delas nesses mercados, assim como de seus papéis e relações com os demais atores envolvidos. Para Souza (2009), a inserção das mulheres no tráfico de drogas se dá pela influência de homens com quem têm relações afetivas e de parentesco, ou de forma independente, por motivações geralmente econômicas.

Nesse sentido, Moki (2005, p. 85) acrescenta que "o desemprego feminino, os baixos salários quando equiparados aos salários dos homens e o aumento de mulheres responsáveis financeiramente por suas famílias" impelem ao exercício de atividades ilícitas, seja no narcotráfico ou em outras modalidades criminosas, seja nas teias dos ilegalismos.

No Conjunto Penal de Juazeiro realizamos entrevistas com mulheres condenadas por crimes da Lei de Drogas, em todos os casos devido ao comércio, ao porte ou ao transporte de quantidades variadas de droga.

A primeira de nossas personagens é Lena, 46 anos. Filha de um engenheiro, falecido, e de uma "merendeira" aposentada, ela cresceu com sete irmãos e avaliou ter tido uma boa infância, mas estudou apenas até a oitava série do Ensino Fundamental, pois uma gravidez precoce interrompeu sua vida escolar. Destino diferente de seus irmãos, que avançaram um pouco mais nos estudos e, na ocasião das entrevistas, estavam empregados. Casou-se aos 17 anos, contrariando a vontade do pai, de quem se afastou gradativamente. Separou-se e tem quatro filhos, que são criados pela ex-sogra. Ela foi presa em duas ocasiões diferentes, em 2009 e 2010, ambas por tráfico de drogas. Sobre sua primeira prisão Lena declarou que, na época do fato, era casada e trabalhava montando barracas em festas, atividade em que, segundo suas palavras, “conheceu gente de todo nível”. Narrou que, em 2008, um dos filhos 
contraiu a Doença de Calazar ${ }^{2}$, que ela estava separada de corpos do marido e que o dinheiro que ganhava não era suficiente para comprar os medicamentos necessários. Nessa época um amigo lhe perguntou se queria vender um “negócio”. Embora tenha ficado com medo, ainda assim pegou dez gramas de "pedra de crack" para vender e continuou vendendo. Passou a vender quantidades maiores e em três meses obteve ganhos de 30 mil reais.

Lena afirmou que o marido, atraído pelo lucro da sua atividade no tráfico, voltou para casa e passou a vender cocaína e crack. Ele "começou a ostentar, subindo e descendo de moto", o que, na cidade pequena, chamou a atenção da polícia. Em uma diligência em sua casa em 2009, ela e o marido foram presos, sendo registrada na ocorrência a apreensão de bebidas, CDs piratas e cinco “dola” de maconha. Segundo Lena, eles não guardavam drogas na casa e a maconha foi plantada pelos policiais. Ela e o marido foram detidos em prisão preventiva por dois e três meses, respectivamente. Quando saíram da cadeia já tinham gastado todo o dinheiro do tráfico, como pagamento ao advogado. Ela contou que não quis mais continuar traficando, mas que seu marido permaneceu na atividade, atraindo a atenção da polícia. Segundo Lena, do "dinheiro do tráfico, tudo que você ganha, você gasta com advogado".

Em 2010, Lena foi presa pela segunda vez. Estava parada, em frente à casa da cunhada, conversando com o sobrinho do marido, quando a polícia apareceu e vasculhou a casa da cunhada, mas não havia droga no local; em suas palavras, a polícia "plantou" na residência maconha e doze "pedras de crack", registrando na ocorrência que a droga lhe pertencia, motivo pelo qual foi presa novamente e passou um ano e quatro meses na cadeia da delegacia da cidade. Lena afirmou ter se separado do marido nessa época, porque ele continuava traficando. Para se manter afastada da atividade ilícita, ela foi morar em outra cidade, onde trabalhou como cozinheira em um restaurante de um posto de gasolina.

Lena contou, ainda, que está cumprindo pena fixada em sentença condenatória, pelo processo de 2009. Ela foi condenada a 22 anos e quatro meses de prisão pelos crimes de falsificação e adulteração de bebidas, de violação de direitos autorais pelos “CDs piratas”, por tráfico de drogas e associação para o tráfico. Foi presa no seu local de trabalho e não pagou advogado, porque não tinha dinheiro, estava trabalhando e não mexia mais com tráfico. Ela continua separada do ex-marido, que também foi preso no Ceará por causa da mesma condenação. Segundo Lena, está correndo o recurso dessa condenação via o advogado do ex-marido.

2. A Doença de Calazar ou Leishmaniose Visceral costuma se propagar nas regiôes rurais, sendo comum no Nordeste brasileiro, e compromete os órgãos viscerais, principalmente o fígado, o baço e a medula óssea. 
Como vimos, Lena reconheceu seu envolvimento voluntário com o tráfico de drogas, motivada por dificuldades financeiras, mas alegou que em ambas as ocasiões em que foi presa não portava drogas. Sua inserção foi mediada por uma figura masculina, mas que não exercia sobre ela influência decorrente de relação de parentesco ou afetividade, pois foi convidada por um conhecido para assumir funções na rede ilícita do circuito de festas no qual ela já trabalhava com comércio informal.

Destacamos que Lena, durante o período em que reconheceu ter traficado, manteve suas funções de mãe, dona de casa e seu trabalho em festas na pequena cidade onde morava. Ela se utilizou da atividade econômica informal, não ilícita, para realizar a venda de substâncias ilícitas, pois se valia dos contatos e do ambiente social para desempenhar sua função no tráfico. Note-se aqui o que Telles (2010, p. 101) chamou de "transversalidade entre o ilegal, o informal e o ilícito", bem como a necessidade de atentarmos para a distinção da "natureza da transgressão que se opera no âmbito da economia informal e a que define as atividades ilícitas ou criminosas, como o tráfico de drogas".

Seu relato demonstra que sobre ela recaiu maior interesse dos agentes de polícia, não só em virtude da aquisição de bens incompatíveis com sua renda, atividade econômica e local de residência, mas também graças ao comportamento do marido. Após a primeira prisão, ela foi rotulada como traficante (Becker, 2008). Em ambas as prisões, todavia, ela não dispôs de meios para acionar o mercado de proteção-extorsão e escapar do flagrante (Misse, 2009; Fraga, 2015) que, segundo sua narrativa, foi forjado pelos policiais.

Ana, outra mulher em cumprimento de pena de restrição de liberdade em Juazeiro, tem 26 anos. Filha de pais separados, ela e oito irmãos foram criados apenas pela mãe, empregada doméstica. Contou que aos 12 anos de idade começou a trabalhar em casa de família, limpava e cuidava de uma criança pequena. Segundo sua avaliação, os "patrões" "tratavam-lhe bem, pagavam direitinho, mas sem carteira assinada". Ela trabalhava até meio-dia e frequentava a escola à tarde, concluindo o sexto ano do Ensino Fundamental. Quando tinha 16 anos, sua mãe foi assassinada pelo companheiro, o que lhe desencadeou um processo depressivo.

Pouco depois disso, outro episódio agravou sua depressão: um colega foi morto a tiros na sua frente. Foi nesse período que, por intermédio de amigos, teve o primeiro contato com as drogas, inicialmente a maconha e depois o crack. Aos 17 anos, uma conhecida the ofereceu uma mistura de maconha e crack (conhecida como "craconha", "criptonita", "mesclado" ou "melado"), que ela passou a usar no cachimbo. Essa mistura a viciou mais rápido: "a droga que faz a pessoa querer cada vez mais, a química dela é um segundo, quando tá fumando, depois que parou de fumar vem a vontade de novo". Ela afirmou que chegou até mesmo a se prostituir para comprar 
a droga, não dormia e raramente se alimentava, pois não sentia vontade de comer. Parou de usar o crack, mas continuou fumando maconha. Em seu entendimento, a maconha a ajudou a deixar o crack, pois lhe fazia bem, aumentava seu apetite e melhorava o sono. Usou drogas durante seis anos e seis meses e parou há cinco anos.

Ana declarou que é "amigada” faz dois anos e não tem filhos. Seu companheiro é usuário de maconha e tomava conta da "boca" em que ela comprava; na ocasião das entrevistas ele também estava preso. Ela disse que conheceu o atual companheiro quando já estava no "mundo das drogas" e que chegaram a traficar juntos: "Ele caiu junto comigo".

Após deixar de fumar crack, ela recuperou a saúde e, hoje, só não está em melhores condições porque foi baleada seis vezes em um atentado motivado por uma rixa envolvendo seu companheiro. Começou a traficar para sustentar o vício, mas depois que parou de usar crack continuou no tráfico para se sustentar. Chegou a lucrar 6 mil reais por semana, apenas com o crack vendido em "peteca" (embalagem plástica). Traficou durante dois anos antes de ser presa, mas não conseguiu comprar uma casa, morava de aluguel e tinha muitas despesas cuidando de três sobrinhos.

Em 2012, Ana foi presa pela primeira vez por transportar quinze quilogramas de maconha e condenada a sete anos de reclusão em regime fechado; após recurso, a pena foi revista e reduzida para dois anos em regime semiaberto. Ela cumpriu um ano, um mês e quinze dias de prisão.

Contou, ainda, que sua segunda prisão ocorreu em 2014. Ela tinha comprado uma televisão sem saber que era roubada, e a polícia fez uma busca na sua casa, encontrando o aparelho, além de droga em uma casa vizinha abandonada. Por ter passagem por tráfico, os policiais disseram que a droga lhe pertencia. Também foi condenada, dessa vez a sete anos e seis meses de reclusão em regime fechado.

A trajetória de Ana difere da de Lena, porque foi marcada pelo abandono do pai, pelo trabalho infantil e por episódios de violência que, segundo seu relato, a levaram ao vício em crack. Embora tenha declarado que traficou em associação com o companheiro, seu ingresso no tráfico ocorreu de forma independente, motivado pela necessidade de manutenção do uso contínuo do crack e, posteriormente, como forma de obtenção de renda.

A terceira entrevistada: Leila, 31 anos. Foi criada inicialmente pelos avós maternos e a partir dos 9 anos, pela mãe e pelo padrasto, junto com dois irmãos; todos receberam "bom estudo", segundo avaliou. Nunca teve contato com o pai biológico. Afirmou ser lésbica - desde muito nova percebeu a diferença em sua orientação sexual. Foi presa duas vezes, acusada pela prática do tráfico de drogas.

Leila contou que, quando cursava o segundo ano do Ensino Médio, começou a se aproximar de homossexuais na escola e a frequentar festas, período em que seu 
relacionamento com a família se tornou mais difícil. Envolveu-se com o tráfico como um trabalho. Com o objetivo de conseguir dinheiro para frequentar festas, ela tomava conta da "boca" de uma amiga que vendia crack em um salão de beleza. A "boca" foi denunciada e ela passou três meses em prisão preventiva, onde conheceu "traficantes fortes", em suas palavras. Acrescentou que, apesar de ser "nova”, não entregou a identidade de ninguém para a polícia e com isso ganhou a confiança dos traficantes. Na audiência de julgamento, Leila declarou que era usuária de drogas e, como a quantidade de crack apreendida era pequena - seis ou oito pedras -, foi liberada pelo juiz já na vigência da lei n. 11.343/2006, apenas com a obrigação de comparecer mensalmente em juízo.

Ao sair da prisão, Leila manteve o contato com os traficantes que conheceu na cadeia e admite que intermediou transações entre estes e algumas amigas, mas que não voltou a trabalhar no tráfico ou a ter participação no lucro.

Sua segunda prisão aconteceu porque ela não deixou de frequentar o local da cidade chamado "campão", conhecido como ponto de venda e de consumo de drogas. Manteve próxima de suas amigas e frequentava o local porque era um ambiente do qual gostava. Contudo, tinha medo, pois “ouvia certas conversas", sabia das dificuldades e das disputas no meio do tráfico, era "matar ou morrer... muito arriscado".

Leila disse que, quando a prenderam em outubro de 2012, estava no "campão" apenas conversando e comprando um "baseado" para uma amiga e foi abordada pela polícia, junto com um adolescente e outro rapaz. Por ser a única com passagem por tráfico, a polícia lhe atribuiu a propriedade de 32 pedras de crack localizadas em buscas no local. Em audiência, ela negou a posse da droga, mas foi condenada a cinco anos e seis meses de reclusão. À época da entrevista, ela já havia cumprido três anos e três meses da sua pena.

A maioria das mulheres presas no Conjunto Penal de Juazeiro, de acordo com seu relato, "caíram" por tráfico. Ela afirmou ter seguido esse caminho "por uma questão familiar, precisava viver". Leila acredita que, na maioria dos casos, as mulheres entram para o tráfico porque têm famílias desestruturadas e por falta de oportunidade. Considera que essas mulheres são "abraçadas" pelo tráfico, o que é "muito ilusório": "o tráfico abre muita porta pra mulheres, mas o homem lidera mais e a mulher é mais usada”.

A trajetória de Leila apresenta uma inserção no tráfico voluntária e mediada por pessoas de seu convívio, ou seja, as amigas com quem se relacionava na busca pela aceitação de sua orientação sexual, e que lhe ofereceram um "trabalho" que proporcionaria dinheiro para sair e se divertir. Sua primeira prisão a inseriu na rede ilícita de tráfico de drogas da região, da qual se manteve próxima. Embora alegue não ter voltado a praticar a atividade, admitiu que foi contatada para indicar um receptador para a droga de uma conhecida da prisão. 
Assim, as trajetórias dessas três mulheres evidenciam sua participação no tráfico para suprir necessidades financeiras, configurando-se um meio de vida. Suas penas foram altas, acima de cinco anos de prisão, e elas se tornaram alvos da repressão policial, que as elegeu de forma seletiva, segundo seus relatos. As mulheres passaram a ser vistas pelas agências de controle do crime como agentes na condução de determinadas tarefas no tráfico de drogas local, tendo sido reprimidas seletivamente.

Os rumos dessas três mulheres indicam formas diferenciadas de inserção no tráfico de drogas, tendo sido levadas ou não para exercerem funções nesse mercado por uma figura masculina. A dependência e a influência de uma figura masculina não são fatores prescindíveis para a compreensão dos caminhos traçados por essas mulheres. No entanto, a condição feminina é elemento marcante para a desproteção a que estão expostas quanto ao risco do encarceramento. Elas possuíam poucos recursos financeiros e interacionais para "desenrolar" com os agentes da repressão policial, e por sua condição de gênero são mais expostas à forma como o ilegalismo se estrutura. Veremos a seguir que, embora a motivação para o ingresso no cultivo ilícito de cannabis no Submédio e Médio São Francisco decorra da situação de vulnerabilidade socioeconômica, as mulheres que se integram nessa atividade raramente são presas, pois a estruturação dos plantios possui componentes importantes destinados à evasão das operações de erradicação feitas pelas polícias federal e militar, dificultando que seus atores sejam alvos da repressão. No tocante às mulheres, observamos que as tarefas por elas desempenhadas favorecem a sua invisibilidade perante as agências de controle penal.

\section{A participação feminina no plantio de cannabis em municípios do Submédio e Médio São Francisco}

Embora o plantio indoor de cannabis tenha crescido nos últimos anos no Brasil, a maior parte da produção é atribuída à modalidade de plantio extensivo, predominantemente na região do Submédio e Médio São Francisco, no Nordeste brasileiro. Como a maioria dos plantios ilícitos extensivos ao redor do mundo, a produção da cannabis no Brasil se consolida como uma cultura de compensação em uma região destinada à agricultura de exportação, submetida à degradação das condições ecológicas e à redução das superfícies cultiváveis. Assim, a cannabis surge como fonte geradora de emprego, renda e melhores condições de vida em um contexto de deterioração da rentabilidade da atividade agrícola lícita (Fraga e Iullianeli, 2011; Gonzales, 2014; Pérez e Laniel, 2004).

Além da vulnerabilidade socioeconômica dos atores envolvidos nos cultivos de plantas ilícitas, outra característica relevante é a influência das estruturas e das 
distinções de gênero, que podem variar de acordo com a região estudada, conforme se depreende dos trabalhos de Pérez e Laniel (2004), Bloomer (2009), Fraga e Iullianeli (2011), Santacruz-De León e Palacio-Muñoz (2014), Afsahi (2015), Fraga (2015), entre outros.

A presença da cannabis é antiga na região do Vale do São Francisco, assim como os registros da participação feminina em seu cultivo. Nesse sentido, Pernambucano (1937) aponta que, no início do século xx, esse plantio era uma tarefa predominantemente feminina, haja vista as roças dessa planta despertarem pouco interesse devido ao baixo valor comercial da atividade. Não obstante, à medida que a maconha foi se tornando uma mercadoria atraente em determinados mercados, os homens se ocuparam do seu comércio para usuários das camadas populares ou indivíduos inseridos nas franjas da marginalidade. Contudo, o cultivo da cannabis em maior escala é um fenômeno mais recente, voltado para atender à demanda do mercado interno, principalmente das capitais nordestinas (Fraga, 2006; 2015).

O incremento da produção ocorreu a partir dos anos de 1980, fazendo com que o polo produtor de cannabis, localizado no entroncamento dos estados da Bahia, Pernambuco, Alagoas e Sergipe, viesse a ser conhecido como "Polígono da Maconha". Na década de 1990, o governo brasileiro deu início ao planejamento e à realização de operações de erradicação de cultivos ilícitos, medidas operacionalizadas, recentemente, pela Delegacia Especializada da Polícia Federal instalada na cidade de Salgueiro, Pernambuco, sobretudo na época da colheita, a fim de debilitar economicamente os plantadores (Fraga, 2015).

Isso motivou que os atores moldassem sua relação com a produção de acordo com a evolução das ações de repressão. Se até os anos de 1980 os plantios eram localizados próximos às principais rodovias ou em glebas de terras pertencentes aos próprios plantadores, a partir da segunda metade dos anos de 1990 e nos anos 2000, foram implementadas novas estratégias de localização das plantações. Em geral, os cultivos foram transferidos para as ilhas de terras que se formam no rio São Francisco, principalmente nos municípios pernambucanos de Orocó e Cabrobó, ou para áreas pertencentes à União no meio da caatinga, com a formação de acampamentos para o cultivo (Idem).

Conforme aponta Fraga (2015, p. 26), nos anos de 1980, quando ocorrem o início do incremento da produção e a expansão do mercado para o produto, "é possível identificar que, apesar da maior presença masculina no plantio, a participação feminina é percebida, ainda que mais timidamente, do que no início do século”.

Nessa época, grande parte do cultivo da cannabis era realizada no sistema de agricultura familiar, com a divisão de tarefas entre todos os membros da família, segundo critérios baseados nas variáveis sexo e idade, com a venda da produção 
para um intermediário ou atravessador, figura conhecida como "boiadeiro". Nesse sistema, o agricultor recebe as sementes do atravessador, que na época da compra da produção desconta o valor das sementes. Por envolver toda a família, as mulheres têm um importante papel e ocupam, geralmente, as tarefas mais delicadas como a separação das plantas machos e fêmeas, o "desgalhamento" na época da colheita e a rega em determinados períodos do dia. Para os homens, na maior parte das vezes, ficam as tarefas mais pesadas e que não requerem tanto detalhamento, como carregar os galóes de água para o plantio. No caso da agricultura familiar, em geral os homens controlam todo o processo (Fraga, 2015; Fraga e Silva, 2015).

Nesse contexto, o papel feminino varia entre a importância destacada em algumas tarefas - garantindo a própria produção e a qualidade do produto - e a invisibilidade. Os homens as desqualificam, mas elas usufruem de certa "proteção" para preservar o eixo produtivo familiar, o que certamente diminui a repressão.

Entamos em contato com as mulheres que tiveram envolvimento com o plantio de cannabis por indicação de agricultores que nunca atuaram nessa área ilícita. As primeiras entrevistadas indicaram outras mulheres que atendiam ao perfil desejado para a pesquisa. Ao todo, entrevistamos nove mulheres, mas, neste artigo, utilizamos para a análise as falas de três delas, como já informado. As três mulheres cujas trajetórias serão descritas a seguir alegaram não mais estarem envolvidas com a atividade.

Laís, 35 anos, exemplifica uma trajetória de inserção no cultivo de cannabis no modelo de agricultura familiar. Filha de um agricultor que já no início dos anos de 1980 plantava cannabis em suas terras, segundo ela, o cultivo estava localizado em uma parte bem distante da sede do sítio e havia pouca repressão policial. $\mathrm{O}$ pai cultivou cannabis durante muitos anos, sempre com o auxílio da família. Quando Laís completou 12 anos de idade, o pai lhe atribuiu algumas tarefas no plantio, como cuidar de mudas, regando-as e separando a planta macho da fêmea. Adulta, casou-se com um agricultor e por sua iniciativa começaram a plantar cannabis no sítio da família. Ela ensinou o marido a cuidar da plantação, mas era ele o responsável por negociar a produção com o atravessador. $\mathrm{O}$ casal permaneceu na atividade durante mais de dez anos, mas deixaram de cultivar a planta devido ao aumento da repressão policial e por temerem a possibilidade de prisão, conforme expresso na seguinte declaração:

Desde pequena eu lido com a maconha. Já passei noites sem dormir e tive muitos sonhos que não presta por causa dela. Sonhava que a polícia me prendia, prendia meu marido, me batia, me xingava. Mas meu pai sobreviveu e criou os filhos por causa do plantio da maconha. Eu sei que não é certo, ele sabia e nos aconselhava a não mexer com a maconha. Ele falava que fazia isso porque não queria ver os filhos morrerem de fome (Laís, 35 anos). 
Laís esclareceu ainda a motivação de seu ingresso no plantio ilícito, demarcando que, apesar dos temores, obteve recursos para superar dificuldades financeiras:

Eu, também, passei dificuldades e foi por causa das dificuldades que eu plantei. Eu não quero plantar mais, hoje eu e meu marido, nós conseguimos sobreviver, graças a Deus, plantando maracujá. Mas não vou mentir, ela me trouxe agonia, mas me deu coisas boas. Mas eu não quero mais. Viver amuado não presta (Laís, 35 anos).

O cultivo de cannabis na região também ocorre no chamado sistema de "meeiro", quando o atravessador, o "boiadeiro", contrata os agricultores para trabalharem em uma roça e o "patrão" (figura geralmente desconhecida pelos plantadores) fornece as sementes, o fertilizante, a "feira" (alimentos a serem consumidos no acampamento) e indica a terra com curso d'água onde será realizado o plantio. Ao fim da colheita, o "patrão" desconta o que investiu e divide o restante entre os agricultores ou, em caso de perda da produção, há a divisão dos prejuízos (Fraga e Silva, 2015).

Nesse sistema de produção, é possível verificar em alguns acampamentos a presença feminina, principalmente, quando a mulher está acompanhada de alguém do sexo masculino, geralmente algum parente, o marido ou o companheiro. Nesses casos, a mulher pode cuidar das plantas pelas quais seu companheiro é responsável ou, também, cozinhar para o grupo ou para algumas pessoas do grupo. Quando as mulheres ficam responsáveis por cozinhar no acampamento, podem receber parte do pagamento em quilogramas de maconha já prensada (Idem).

A inserção feminina nesse sistema pode ser representada pela história de Telma, 32 anos. Ela é filha de agricultores que foram deslocados de suas terras após a construção da barragem de Itaparica, no rio São Francisco. A família residiu e trabalhou em pequenos sítios até conseguir se estabelecer em uma agrovila, onde o pai iniciou uma pequena roça de subsistência, cuja produção mal supria as necessidades básicas. Aos 16 anos, começou um relacionamento com um jovem de 20 anos, com quem teve dois filhos e viveu por quatro anos. Os filhos presenciavam as constantes brigas do casal, inclusive as agressões físicas sofridas pela mãe, o que levou à separação do casal. Telma mudou-se de cidade e começou a trabalhar em um pequeno comércio. Lá conheceu um pequeno agricultor, com quem veio a se casar. Ela teve o primeiro contato com o plantio de cannabis por intermédio do marido, pois, durante um período do ano, ele trabalhava em acampamentos de cidades próximas da residência do casal.

Telma, no princípio, temia a atividade de seu companheiro, motivo pelo qual quase se separou. Contuto, a atividade proporcionava-lhes uma vida confortável que, segundo sua avaliação, eles não obteriam fora da atividade ilícita. Ela manteve seu trabalho e cuidava dos filhos, mas por causa de um desentendimento com o gerente do 
estabelecimento deixou o emprego e ficou apenas na atividade doméstica. Dificuldades familiares, entretanto, a levaram a aceitar o convite do marido para participar no plantio de cannabis. Fazia a "feira" para o acampamento, comprando os mantimentos necessários para os agricultores que trabalhavam no plantio. Depois tomou a iniciativa de permanecer acampada, como outras mulheres, que também acompanhavam seus maridos no plantio de cannabis. Durante quatro anos trabalhou na atividade, mas abandonou o cultivo ilícito por temer ser presa junto com seu marido e ter de deixar seus filhos com a mãe, que também dependia do dinheiro proveniente da renda da cannabis. Quando questionada sobre a possibilidade de regressar à atividade, Telma respondeu que, caso viesse a necessitar muito, voltaria a plantar. Seu marido também não está mais na atividade; eles nunca foram presos e conseguiram montar um pequeno comércio em sua cidade com o dinheiro ganho no plantio.

A inserção feminina nos plantios de cannabis realizados no sistema de "meeiro" é bem menor que aquela que ocorre no sistema de agricultura familiar. Isso se deve a alguns fatores, elencados por Fraga e Silva (2015) e Fraga (2015), quais sejam: (1) localização distante das roças, plantadas em áreas de difícil acesso (normalmente terras da União em meio à caatinga, muito longe das rodovias e de cursos d'água, ou em ilhas ao longo do rio São Francisco); (2) necessidade de isolamento total (regime de "internação") nos acampamentos durante todo o período entre o plantio e a colheita (em média quatro meses), vivendo em condições de higiene precárias; (3) violência da atividade, que registrava índices elevados de homicídio em determinado período de tempo; (4) o fato de a atividade durante a época de cultivo ser apontada por alguns agricultores entrevistados como um trabalho muito pesado para as mulheres, por requerer dispêndio significativo de força física, principalmente na rega da plantação onde não há irrigação; (5) grande risco de prisão devido à intensificação da repressão policial; e (6) necessidade de cuidado com os filhos, principal razão do temor à prisão. $O$ fator gênero é um elemento importante para a não participação mais efetiva da mulher nessa modalidade.

Por fim, um sistema de cultivo mais recente, ainda pouco usual, nomeado aqui de "consórcio", ocorre quando duas ou mais pessoas elegem uma terra de difícil acesso, pública ou abandonada, para dificultar a repressão policial e impedir a expropriação judicial caso a plantação seja detectada. Depois de escolhido o local, esse grupo adquire a semente da planta, que é paga imediatamente ou após a colheita. Normalmente, o fornecedor da semente tem o monopólio da compra do produto. O grupo contrata algumas pessoas para trabalhar na roça, as quais serão pagas após a colheita e a venda da produção. Um exemplo da inserção feminina nesse sistema é Josenaide, 34 anos. Ela nasceu em uma família de pequenos agricultores que sofreram constantes dificuldades financeiras. Sua mãe faleceu quando tinha 15 anos e, por ser 
a filha mais velha, teve que assumir as tarefas domésticas. Aos 19 anos, foi trabalhar em um sindicato de trabalhadores rurais de sua cidade. Lá, conheceu agricultores que tinham uma história de envolvimento com o plantio de cannabis na região. Após conversa com alguns desses agricultores, apesar do medo de se envolver em uma atividade ilícita, resolveu participar de uma operação de "consórcio", conforme seu depoimento:

No início eu tive muito medo, pois todos aqui sabem das operações da Federal que têm muitos homens e utilizam helicóptero e tudo. Mas, quando pegamos uma terra, colocamos as sementes e colocamos pessoas para trabalhar, o risco é menor. Eu fiquei nisso algumas vezes. Ganhei um bom dinheiro que usei para pagar dívidas e melhorar minha vida (Josenaide, 34 anos).

Segundo Josenaide, a atividade era muito lucrativa, mas por temer alguma denúncia, deixou de participar. Quando questionada sobre a possibilidade de retornar à prática, ela afirmou não saber responder, mas que espera não precisar por conta dos riscos envolvidos.

Nenhuma dessas três mulheres, assim como as outras seis que entrevistamos, foi presa ou teve qualquer problema com a justiça, nem sofreu perseguição ou repressão das agências policiais. É incomum, igualmente, encontrar processos contra mulheres por envolvimento no plantio de cannabis nas comarcas das cidades do Submédio e Médio São Francisco. Nas duas pesquisas, encontramos somente dois processos. Um em Cabrobó, envolvendo uma adolescente de 17 anos, que foi processada pela prática de ato infracional referente ao cultivo de cannabis, junto com o irmão e um primo, também menores, ainda na vigência da lei n. 6.368 de 1976. Na operação da polícia federal também foram presos uma irmã dessa adolescente, maior de idade, e outros adultos. Os três adolescentes cumpriram medida socioeducativa de liberdade assistida pelo período de um ano com a obrigação de comprovarem a frequência escolar.

Outro processo encontrado em Orocó envolveu uma mulher, presa durante uma operação da polícia militar motivada por denúncias sobre plantios ilícitos, já na vigência da atual Lei de Drogas. A mulher foi detida nas proximidades do local em que policiais haviam erradicado uma roça de cannabis, quando estava na casa do ex-companheiro, onde foram encontrados pouco mais de 454 quilogramas da droga armazenada em sacos enterrados no quintal e 5.800,00 reais em espécie. Mesmo alegando desconhecer a origem da droga e de seu proprietário, a mulher foi condenada a cinco anos e dez meses de prisão pelo crime de tráfico de drogas (art. 33, caput, da lei n. 11.343/2006). O pequeno número de processos criminais de mulheres deve-se ao fato de que elas recebem maior proteção no sistema de plantio, sobretudo em lugares onde há envolvimento de outros familiares, diferentemente do 
que ocorre no tráfico urbano. A mulher passa a ser o elo fundamental de manutenção do sistema de agricultura familiar se o marido é preso. Nesse sistema, em uma parte do ano planta-se cannabis, mas no outro período vive-se da agricultura tradicional. A relação entre o lícito e o ilícito é tênue e compõe a dinâmica desse ilegalismo.

A repressão policial recai mais sobre os homens, principalmente por causa da invisibilidade feminina no plantio, fato comum em outros contextos (Afsahi, 2015; Gonzales, 2014), mas o trabalho feminino é fundamental para o desenvolvimento dos cultivos. No entanto, essa proteção e invisibilidade estão atreladas também às estratégias de repressão ao plantio. Nesse sentido, as alterações da forma de cultivo, concentrada mais no modelo de agricultura familiar, graças às novas estratégias de enfrentamento da repressão, poderão retirar as mulheres da invisibilidade em que se encontram atualmente. A questão de gênero, em mudança, reflete-se no maior protagonismo feminino e nas estratégias de gestão do ilegalismo, o que pode levar ao aumento da repressão e do encarceramento de mulheres. Mas isso é questionável, uma vez que a mulher tem um papel primordial na economia familiar e no cuidado com os filhos, e por isso se mantém mais protegida.

\section{Considerações finais}

As mulheres presas por tráfico de drogas relataram sua inserção em contextos favoráveis à construção de uma carreira criminal e à rotulação como traficantes (Becker, 2008), graças ao desempenho de funções marcadas por maior visibilidade, que as tornaram mais sujeitas à repressão policial e à violência presente nesse mercado.

A maior visibilidade das funções desempenhadas por essas três mulheres nos mercados de drogas ilícitas da região decorre da configuração dessa atividade, moldada e gerida pelas condições políticas, pelos rigores repressivos e pelos diferentes critérios de incriminação inseridos nas práticas de proteção-extorsão das forças policiais. Por não disporem dos meios para se favorecerem nesse campo de forças, elas sofrem mais severamente sujeição-criminal (Misse, 1999). Além disso, como consequência da primeira prisão e das sociabilidades locais, elas permanecem em meio a uma rede de ilegalismos, vinculados ou não a grupos criminosos (Telles, 2010). Isso leva a novas prisões e ao agravamento das penas a elas atribuídas em razão da reincidência nos crimes da Lei de Drogas, bem como a um maior tempo de permanência no sistema prisional, visto que, como as três entrevistadas, a maioria das presas não dispõe de recursos financeiros ou assistência familiar para arcarem com os custos dos processos judiciais.

Já as mulheres que admitiram envolvimento no cultivo ilícito de cannabis desempenharam atividades específicas, que requeriam maior atenção e cuidado, e 
influenciaram no aumento da produtividade e da rentabilidade dos cultivos, especialmente na agricultura familiar, em um contexto em que não foram pressionadas para traçar uma carreira criminal e que lhes conferiu certa invisibilidade e proteção ante a repressão policial.

As trajetórias das três mulheres envolvidas no plantio de cannabis refletem algumas das formas por meio das quais elas são inseridas e passam a desempenhar funções nessa atividade ilícita. Não obstante, destacamos que, hoje, a atividade de cultivo ilícito na região do Submédio e Médio São Francisco é predominantemente masculina por desenvolver-se, ainda, no sistema de "meeiro", ou seja, em acampamentos isolados (Fraga e Silva, 2015). Contudo, citando o relato de policial federal da Delegacia Especializada de Salgueiro, em Pernambuco, Fraga (2015) chama a atenção para o fato de que o aumento do combate ao cultivo ilegal nos últimos anos, com o emprego de recursos tecnológicos como os satélites e helicópteros, afetou a configuração das roças de cannabis, provocando a concentração da produção nas ilhas do rio São Francisco, pulverizando pequenas roças ao longo das terras marginais ao rio e alterando as redes de produção-escoamento. Isso causou o aumento da inserção de famílias de agricultores ou trabalhadores rurais mais pobres no processo produtivo. Essa intensificação da produção pulverizada, em menor quantidade no “continente", tende a fazer com que a participação feminina aumente em relação a outros períodos, em especial quando atrelada, também, à produção familiar. Todavia, ainda é cedo para confirmar tal tendência, pois a produção no sistema de agricultura familiar deixa o agricultor mais vulnerável à repressão policial (Fraga e Silva, 2015).

Por outro lado, cumpre destacar que as mulheres que se envolvem no cultivo o fazem de forma diferenciada em relação aos homens, pois, em lugar de um ingresso independente, ainda é comum a mediação de uma figura masculina com quem elas tenham relação afetiva, como marido, companheiro, irmão ou pai. Entretanto, como no caso de Josenaide, observamos mulheres que assumem um papel de protagonismo e de liderança. Isso também reflete a maior participação das mulheres em muitas atividades laborais e de liderança no sertão pernambucano, região em que o machismo ainda é muito presente nas atividades cotidianas (Idem).

Nas entrevistas com as mulheres envolvidas no plantio ilícito, percebe-se que, se comparadas com os homens, há diferença na forma como investem o dinheiro ganho com a cannabis. Enquanto eles, principalmente os mais jovens, utilizam a maior parte do recurso em atividades como festas, na compra de motos e outros bens que irão lhes conferir distinção, as mulheres voltam boa parte dos recursos para a melhoria das condições de vida da família, seja investindo na educação dos filhos, na abertura de um pequeno negócio ou na compra de bens que lhes proporcionam maior qualidade de vida e, segundo suas avaliações, mais conforto (Idem). 


\section{Referências Bibliográficas}

Afsahi, K. (2015), "Pas de culture de cannabis sans les femmes: le cas du Rif au Maroc". Déviance et Société, 39 (1): 73-97.

BARBOSA, A. R. (1998), Um abraço para todos os amigos: algumas consideraçôes sobre o tráfico de drogas no Rio de Janeiro. Niterói, Eduff.

Barros, A. M. et al. (2007), "Criminalidade e análise de gênero - a mulher e o crime: um estudo na penitenciária de Garanhuns-PE”. Disponível em http://www.ufpe.br/ppgdh/ images/documentos/anamb3.pdf, consultado em 12/12/2014.

Becker, H. S. ([1963] 2008), Outsiders: estudos de sociologia do desvio. Rio de Janeiro, Jorge Zahar.

Bloomer, J. (2009), "Using a political ecology framework to examine extra-legal livelihood strategies: a Lesotho-based case study of cultivation of and trade in cannabis". Journal of Political Ecology, 16: 49-69.

Boiteux, L. (2009), "Breve histórico do controle internacional de drogas". In: Boiteux, L. et al. (2009), Tráfico de drogas e Constituição: um estudo jurídico-social do tipo do art. 33 da Lei de Drogas diante dos princípios constitucionais-penais. Relatório final do Projeto de pesquisa apresentado ao Ministério da Justiça/pnud, no Projeto "Pensando o Direito", Referência Prodoc BRA/08/001. Rio de Janeiro/Brasília, Universidade Federal do Rio de Janeiro/Universidade de Brasília.

. (2015), "A guerra contra as drogas é uma guerra contra as mulheres". Disponível em http://www.brasil247.com/pt/colunistas/pauloteixeira/204325/A-guerra-contraas-drogas-é-uma-guerra-contraas-mulheres.htm), consultado em 20/10/2016.

BRASIL/Ministério da Justiça. Departamento Penitenciário Nacional. (2015), Levantamento nacional de informaçōes penitenciárias - Infopen Mulheres. Brasília, DF.

BRAUNSTEIN, H. R. (2007), Mulher encarcerada: trajetória entre a indignação e o sofrimento por atos de humilhação e violência. São Paulo, dissertação de mestrado, Faculdade de Educação da Universidade de São Paulo.

CAmpos, Marcelo da Silveira. (2015), Pela metade: as principais implicações da nova lei de drogas no sistema de justiça criminal em São Paulo. São Paulo, tese de doutorado em sociologia, Faculdade de Filosofia, Letras e Ciências Humanas da Universidade de São Paulo.

Carvalho, S. (1997), A politica criminal de drogas no Brasil: do discurso oficial às razóes de descriminalização. Rio de Janeiro, Luam.

D'elia Filho, O. Z. (2007), Acionistas do nada: quem são os traficantes de drogas. Rio de Janeiro, Reavan.

Dubar, C. (1998), "Trajetórias sociais e formas identitárias: alguns esclarecimentos conceituais e metodológicos". Educação e Sociedade, 19 (62): 13-30. Disponível em http://dx.doi. org/10.1590/S0101-73301998000100002, consultado em 12/5/2015. 
Foucault, M. (1997), Vigiar e punir: História da violência nas prisões. Petrópolis, Vozes.

Fraga, P. C. P. (2006), "Plantios ilícitos no Brasil: notas sobre a violência e o cultivo de cannabis no polígono da maconha”. Cadernos de Ciências Humanas-Especiaria, 9 (15): 95-118. . (2014), "A participação feminina no plantio de cannabis no Vale do São Francisco". In: Fraga, P. C. P. (org.). Mulheres e criminalidade. Rio de Janeiro, Letra Capital, vol. 1, pp. 14-35.

Fraga, P. C. P.; Cunha, S. M \& Carvalho, L. C. (2014), "Políticas de repressão e erradicações de plantios de cannabis no Nordeste brasileiro". In: FraGa, P. C. P. Plantios ilícitos na América Latina. Rio de Janeiro, Letra Capital, pp. 55-80.

\& Iulianelli, J. A. S. (2011), "Plantios ilícitos de cannabis no Brasil: desigualdades, alternativa de renda e cultivo de compensação”. Revista Dilemas, 4 (1): 11-40.

\& Silva, J. K. N. (2015). "Mulheres e criminalidade: um estudo acerca do envolvimento de mulheres com o plantio de cannabis no Vale do São Francisco". Trabalho apresentado no XVII Congresso Brasileiro de Sociologia, 20 a 23 de julho de 2015, Porto Alegre, RS.

(2016). "As ações de contenção aos plantios ilícitos no Brasil: repressão policial e políticas governamentais”. Revista Debates Latinoamericanos, 14: 72-88.

Freire, A. K. S. et al. (2014), "Uso de substâncias psicoativas por estudantes rurais: distribuição por sexo e idade”. Revista de Enfermagem UFSM, 4 (4): 803-812.

FRINHANI, F. M. D. (2004), Mulheres encarceradas: representando o universo prisional. Espírito Santo, dissertação de mestrado em psicologia, Universidade Federal do Espírito Santo.

Goffman, E. (1988), Estigma: notas sobre a manipulação da identidade deteriorada. Rio de Janeiro, Guanabara Koogan.

Gómez, A. S. (2012), Las jefas del narco: el ascenso de las mujeres en el crimen organizado. México, Random House Mondadori.

Gonzales, L. C. (2014), "Consecuencias sociales del cultivo de la coca em comunidades afrocolombianas del Caquetá: análisis dela relación entre la economía ilícita, las prácticas campesinas tradicionales y su papel en la seguridad alimentaria”. Ágora U.S.B. [on-line], 14 (1): 203-221.

Grillo, C. C. (2008), "O morro e a pista: um estudo comparado de dinâmicas do comércio ilegal de drogas". Dilemas: Revista de Estudos de Conflito e Controle Social, 1: 127-148.

Guedes, M. A. (2006), "Intervenções psicossociais no sistema carcerário feminino”. Psicologia Ciência e Profissão, 26 (4): 558-569.

HeCKathorn, D. D. (1997). "Respondent-driven sampling: a new approach to the study of hidden populations". Social Problems, 44 (2): 174-199.

HeLPES, S. S. (2015), Vidas em jogo: um estudo sobre mulheres envolvidas com o tráfico de drogas. São Paulo, IBCCRIM.

Kokoreff, M. (2005), "Toxicomanie et trafics de drogues: diversité des cheminements et effets de génération au sein des milieux populaires en France”. In: Brunelle, N. \& Cousineau, 
M. (eds.), Trajectoires de déviance juvénile: les éclairages de la recherche qualitative. Quebec, Presses de L'Université du Québec, pp. 31-60.

Lemgruber, J. (1983), Cemitério dos vivos: análise sociológica de uma prisão de mulheres. Rio de Janeiro, Edições Achiamé.

Misse, M. (1999), Malandros, marginais e vagabundos: a acumulação social da violência no Rio de Janeiro. Rio de Janeiro, tese de doutorado, Instituto Universitário de Pesquisas do Rio de Janeiro.

Moki, M. P. (2005), Representaçôes sociais do trabalho carcerário feminino. São Carlos, dissertação de mestrado, Universidade Federal de São Carlos.

Moreira, E. M. (2007), A criminalização dos trabalhadores rurais no Polígono da Maconha.

Niterói, dissertação de mestrado, Programa de Pós-graduação em sociologia e direito da Universidade Federal Fluminense.

Nóbrega Júnior, J. M. P. (2010), Os homicídios no Brasil, no Nordeste e em Pernambuco: dinâmica, relaçôes de causalidade epolíticas públicas. Recife, tese de doutorado, Universidade Federal de Pernambuco.

Oliveira, A. (2007), "As peças e os mecanismos do crime organizado em sua atividade tráfico de drogas”. Dados: Revista de Ciências Sociais, 50 (4): 699-720.

Oliveira, W. A. V. (2015), "Mulheres negras e presidiárias na busca por direitos humanos através das ações (programas, projetos e políticas) sociais de ressocialização”. Trabalho apresentado no 39 Encontro Anual da Anpocs, 26 a 30 de outubro, Caxambu, MG.

Pérez, P. \& LANiel, L. (2004), “Croissance et croissance de l'économie du cannabis en Afrique subsaharienne (1980-2000)”. Hérodote, 112: 122-138.

Pernambucano, J. (1937), “A maconha em Pernambuco”. In: Freyre, Gilberto (org.). Novos estudos afro-brasileiros. Rio de Janeiro, Civilização Brasileira, 1937.

Poupart, J. (2010), “A entrevista de tipo qualitativo: considerações epistemológicas, teóricas e metodológicas”. In: Poupart, J. et al. (orgs.). A pesquisa qualitativa: enfoques epistemológicos e metodológicos. Petrópolis, Vozes, 2010, pp. 215-253.

Ribeiro, A. M. M. (2008), O polo sindical do Submédio São Francisco: das lutas por reassentamento à incorporação do cultivo de maconha na agenda. Rio de Janeiro, tese de doutorado, Instituto de Ciências Humanas e Sociais da Universidade Federal Rural do Rio de Janeiro.

Rodrigues. L. B. \& Ribeiro, M. da S. (2015), “Obtenção de renda pelo 'usuário de crack’: uma relação entre qualificação para o mercado de trabalho e o uso compulsivo". In: DUQUE, Ghilane (org.). Pesquisa e teoria nas ciências sociais: o exercício do diálogo. Curitiba, cVC, pp. 5-156.

Salganik, M. J.; Heckathorn, D. D. (2004), "Sampling and estimation in hidden populations using respondent-driven sampling”. Sociological Methodology, 34: 193-240.

Santacruz-De León, E. E. \& Palacio-Muñoz, V. H. (2014), “Campesinos mexicanos: entre la subsistencia, el mercado y los cultivos ilícitos”. Quivera, 16 (2): 11-25.

SAntos, C. C. A. T. (2009), Um olhar sobre a colônia penal feminina do Recife: dinâmica e 
compreensão do perfil da mulher no cárcere. Recife, monografia, Curso de Aperfeiçoamento/Especialização em Políticas e Gestão em Segurança Pública da Faculdade Integrada do Recife, Ministério da Justiça.

Silva, J. K. N. (2015), "Mulheres no tráfico de drogas: um estudo sobre os determinantes da condenação na cidade de Juiz de Fora”. In: FraGa, P. C. P. (org.). Mulheres e criminalidade. Rio de Janeiro, Letra Capital, pp. 37-80.

Soares, B. M.; Ilgenfritz, I. (2002), Prisioneiras: vida e violência atrás das grades. Rio de Janeiro, Garamond.

SolHet, R. (1989), Condição feminina e formas de violência: mulheres pobres e ordem urbana, 1890-1920. Rio de Janeiro, Forense Universitária.

Souza, K. O. J. (2009), "A pouca visibilidade da mulher brasileira no tráfico de drogas". Revista Psicologia em Estudo, Maringá, 14 (4): 649-657.

Telles, V. S. (2009), “Ilegalismos urbanos e a cidade”. Novos Estudos Cebrap, 84: 153-173. (2010), "Nas dobras do legal e do ilegal: ilegalismos e jogos de poder nas tramas da cidade”. Dilemas: Revista de Estudos de Conflito e Controle Social, 2 (5-6): 97-126.

Telles, V. S \& Hirata, D. V. (dez. 2010), "Ilegalismos e jogos de poder em São Paulo". Tempo Social, 22 (2): 39-59. Disponível em http://www.scielo.br/scielo.php?script=sci_ arttext\&pid=S0103-20702010000200003\&lng=pt\&nrm=iso.

VINUto, J. (ago./dez. 2014), “A amostragem em bola de neve na pesquisa qualitativa: um debate em aberto”. Temáticas, 22 (44): 203-220. 


\section{Resumo}

A participação feminina em mercados ilícitos de drogas no Vale do São Francisco, no Nordeste brasileiro

$\mathrm{O}$ artigo propõe-se a fazer reflexões com base em dados de pesquisas que analisam a participação feminina nos crimes de drogas em cidades do Submédio e Médio São Francisco, no Nordeste brasileiro. Destacamos a análise do relato de vida de seis mulheres que estiveram envolvidas no comércio ilegal de drogas e no plantio de cannabis sativa. O objetivo é contribuir para a discussão teórica sobre as relações existentes entre a condição de gênero e os mecanismos, as práticas e os atores dos mercados ilícitos de drogas na região, bem como analisar dois aspectos relacionados à gestão dos ilegalismos atrelados às drogas em contextos distintos: a qualidade da participação feminina nas atividades de plantio e de tráfico e os efeitos diferenciados produzidos nessas atividades para as mulheres em cidades do sertão baiano e pernambucano.

Palavras-chave: Histórias de vida; Gênero; Tráfico de drogas; Plantios ilícitos; Repressão policial.

\section{Abstract}

Female participation in illicit drug markets in Valley of the São Francisco River, Northeastern Brazil This paper presents some reflections based on data from researches that analyzes the female participation in drug crimes in Valley of the São Francisco River, in northeastern Brazil. It presents the analysis of the life stories of six women who were involved in the illegal drug trade and in planting cannabis sativa. The objective is to contribute to the theoretical discussion about the relationship between the gender condition and the mechanisms, practices and actors of illicit drug markets in the region, as well as to analyze two effects related to the ilegalism management of drug-related in different contexts: quality of female participation in planting and trafficking activities and the differential effects produced in these activities for women in cities in the Sertão region of Bahia and Pernambuco.

Keywords: Life histories; Gender; Drug trafficking; Illicit plantations; Police repression.

Texto recebido em 19/3/2017 e aprovado em 24/3/2017. DoI: 10.11606/0103-2070.ts.2017.1 28528 .

PAUlo CeSAR pOntes fRaga é professor adjunto do Departamento de Ciências Sociais da Universidade Federal de Juiz de Fora. E-mail: pcp_fraga@yahoo.com.br.

JOYCE KELI DO NASCimento Silva é doutoranda do Programa de Pós-graduação em Ciências Sociais da Universidade Federal de Juiz de Fora. E-mail: joycekeli@gmail.com. 
